\title{
SEMIOLOGIA PSIQUIÁTRICA
}

\author{
PSYCHIATRIC SEMIOLOGY
}

Antonio Waldo Zuardi, Sonia Regina Loureiro

\begin{abstract}
Docentes do Departamento de Neurologia, Psiquiatria e Psicologia Médica da Faculdade de Medicina de Ribeirão Preto da Universidade de São Paulo

CorRespondência: Antonio Waldo Zuardi - Departamento de Neurologia, Psiquiatria e Psicologia Médica da Faculdade de Medicina de Ribeirão Preto - Campus Universitário - CEP: 14.048-900 - Ribeirão Preto - SP.
\end{abstract}

ZUARDI AW \& LOUREIRO SR. Semiologia psiquiátrica. Medicina, Ribeirão Preto, 29: 44-53, jan./mar. 1996.

RESUMO: O objetivo principal deste artigo é introduzir o estudante de graduação, especialmente de Medicina, na prática da semiologia psiquiátrica. Os autores discutem a entrevista psiquiátrica como a maneira essencial de avaliação do paciente psiquiátrico. $O$ artigo fornece uma visão geral da história psiquiátrica e das partes componentes do exame do estado mental, incluindo: aparência, fala e pensamento, distúrbios da percepção, afeto e humor, atenção e concentração, memória, orientação, consciência, inteligência e julgamento da realidade.

UNITERMOS: Anamnese. Psiquiatria. Relações Médico-Paciente. Entrevista Psiquiátrica.

\section{INTRODUÇÃO}

Os dados necessários à História Clínica Psiquiátrica e ao Exame do Estado Mental, são obtidos, basicamente através da entrevista psiquiátrica, estando sujeitos à influência de inúmeras variáveis, relacionadas ao entrevistador, ao entrevistado (paciente, familiar ou outro informante), à interação entre eles e ao ambiente onde o exame está sendo realizado.

Características do entrevistador, como suas crenças, valores, sensibilidade, estado emocional no momento da entrevista e outras, podem interferir nos fenômenos observados. A forma como uma pergunta é formulada, o tom de voz utilizado, um olhar, um gesto, poderão orientar a resposta do paciente.

Variáveis do paciente, também interferem na obtenção dos dados, por exemplo, sua motivação em relação ao exame. Se o paciente procurou ajuda, espontaneamente, pode-se esperar que tenha uma certa preocupação com seu estado e uma predisposição maior em colaborar. A situação daquele que foi trazido contra sua vontade é, seguramente bem diversa ${ }^{1}$.
A interação entre o entrevistador e o paciente, não se constitui, necessariamente, numa distorção das condições "naturais" de observação, se considerarmos que a conduta humana ocorre sempre "num contexto de vínculos e relações humanas" e não isoladamente ${ }^{2}$. Assim, a situação de entrevista psiquiátrica constitui-se numa forma particular de interação, que ocorre dentro de um campo delimitado pelos seus objetivos, adquirindo características próprias. Um dos integrantes deste relacionamento é um profissional, que deve usar seus conhecimentos para entender o que está acontecendo com o outro e que deverá interagir de acordo com esta compreensão. O paciente, por outro lado, necessita e, em geral, espera obter auxílio do profissional, o que deve estimulá-lo a falar e refletir sobre si mesmo, ainda que, o paciente psiquiátrico ao mesmo tempo que está motivado para revelar-se, pode ocultar sentimentos íntimos, por conta de suas defesas psíquicas $^{3}$. De qualquer forma, a interação é uma das variáveis que influencia a observação, por exemplo, a eclosão de sentimentos de simpatia ou antipatia, pode influir no resultado do exame ${ }^{4}$. 
Variáveis do ambiente onde o exame é conduzido, também interferem com o mesmo, por exemplo o local, a duração, a disposição espacial dos participantes e as condições de privacidade.

O conhecimento dessas variáveis e o preparo técnico do entrevistador, contribuem para que ele estimule a comunicação do entrevistado com um mínimo de interferência, permitindo que o campo da entrevista seja configurado, fundamentalmente, pela personalidade e psicopatologia do entrevistado.

Existem diferentes tipos de entrevistas que, de uma maneira bastante ampla, poderiam ser agrupadas em: abertas, estruturadas e semi-estruturadas.

$\mathrm{Na}$ entrevista aberta, o entrevistador não segue um roteiro rígido e pré-determinado, permitindo que o entrevistado fale o mais livremente possível, de tal forma que o curso da entrevista seja por ele determinado $^{2}$. Este tipo de entrevista permitiria um acesso mais fácil ao material inconsciente, através da observação da ordem em que os assuntos são comunicados, da associação entre os mesmos, das interrupções, das respostas emocionais, etc. Suas principais limitações são: a pequena possibilidade de concordância entre diferentes entrevistadores; a dificuldade para formulação de diagnósticos consistentes, em razão da investigação assistemática dos sintomas; o tempo imprevisível e, muitas vezes, longo para a obtenção de informações.

Nas entrevistas estruturadas, a forma pela qual se obtém as informações, a sequiência das perguntas e os registros dos resultados são pré-determinados. Geralmente, os formulários dessas entrevistas contém glossários, que procuram descrever, acuradamente, os termos empregados. A principal vantagem desse tipo de entrevista é aumentar a confiabilidade do diagnóstico psiquiátrico, facilitando a concordância entre diferentes profissionais. Em razão disso, as entrevistas estruturadas tem se constituído em importante instrumento para as atividades de pesquisa clínica e estudos epidemiológicos $^{5}$. Pode-se questionar a pequena flexibilidade desse tipo de entrevista, o que, em determinadas circunstâncias, poderia prejudicar a colaboração do paciente.

As entrevistas semi-estruturadas, tem um nível de estruturação maior ou menor, dependendo da entrevista, mas permitem sempre uma certa flexibilidade na seqüência e/ou forma de formular as perguntas. Várias entrevistas semi-estruturadas são padronizadas, estabelecendo os limites dessa flexibilidade. Estas entrevistas, em geral, mantém níveis elevados de confiabilidade.

As entrevistas psiquiátricas habituais, embora não padronizadas, podem ser consideradas do tipo semi-estruturada, porque o entrevistador, de alguma forma, procura, ativamente, obter dados que lhe permitam preencher uma história clínica e elaborar um exame das funções mentais, seguindo algum roteiro, mesmo que não claramente explicitado. Assim, é importante que o psiquiatra tenha sempre presente uma estrutura de história clínica e exame do estado mental, que lhe permita dirigir a entrevista, sem perder a dimensão do todo a ser explorado. Um roteiro de anamnese e exame psicológico é apresentado na Tabela I.

Tabela I - Tópicos a serem avaliados e registrados na Anamnese Psiquiátrica

1. Identificação.

2. Queixa Principal

3. História da Moléstia Atual.

4. Antecedentes - História Médica e Psiquiátrica.

5. Antecedentes - História Pessoal:

a) História Pré-Natal / Nascimento.

b) Infância - desenvolvimento.

c) Adolescência.

d) Idade Adulta.

6. Antecedentes - História Familiar

7. Personalidade Pré-Mórbida.

8. Exame Físico.

9. Exame Psiquiátrico

Apresentação

- Aparência

- Psicomotricidade

- Situação da entrevista

Linguagem e Pensamento

- Característica da fala

- Progressão da fala

- Forma do pensamento

- Conteúdo do pensamento

- Capacidade de abstração

Senso-Percepção

Afetividade e Humor

- Tonalidade emocional

- Modulação

- Associação pensamento/afeto

- Equivalentes orgânicos

Atenção e Concentração

- Manutenção

- Focalização

- Desatenção seletiva

Memória

- Remota

- Recente

- Imediata

Orientação

- Autopsíquica

- Alopsíquica

Consciência

Capacidade intelectual

Juízo Crítico da Realidade 
A avaliação psiquiátrica começa antes mesmo do início da entrevista, com a observação da expressão facial do paciente, seus trajes, movimentos, maneira de se apresentar, etc. Como a colaboração do paciente é fundamental para a obtenção dos dados, o esforço inicial do entrevistador deve ser no sentido de estabelecer um contacto que permita ao paciente sentir-se à vontade para expor suas dificuldades. O início da entrevista deve ser pouco diretiva, permitindo a livre expressão do paciente, com interferência mínima do entrevistador e apenas com o objetivo de esclarecer pontos obscuros do relato. Após a exposição inicial do paciente, o entrevistador deve adotar um papel mais ativo, conduzindo a entrevista, com tato, para cobrir todos os aspectos da anamnese. É importante salientar que o entrevistador deve adaptar sua entrevista ao paciente e não forçar o paciente a adaptar-se à entre$v^{\text {vista }}{ }^{6}$. No decorrer da entrevista, é importante atentar-se não apenas ao que o paciente diz, mas também à forma como se expressa e ao que faz enquanto fala. Igualmente importante é a auto-observação do entrevistador para suas próprias reações diante do paciente. $\mathrm{Na}$ parte final da entrevista, o entrevistador pode fazer perguntas mais diretas para esclarecer os pontos que faltem para completar a história psiquiátrica ou o exame do estado mental. Antes de finalizar a entrevista, o entrevistador deve abrir um espaço para comentários adicionais do paciente, esclarecer suas dúvidas e, em seguida, formular sua impressão até aquele momento. Quando necessário, devem ser conduzidas entrevistas adicionais e consultas a outras fontes de informação, tais como, parentes ou conhecidos, sempre com o prévio conhecimento e anuência do paciente.

\section{HISTÓRIA CLÍNICA PSIQUIÁTRICA}

A História Clínica Psiquiátrica ou Anamnese Psiquiátrica objetiva fornecer elementos para a formulação diagnóstica, incluindo a descrição detalhada dos sintomas e a identificação dos fatores predisponentes, precipitantes e perpetuantes da doença ${ }^{6}$. Consiste, ainda, em uma caracterização da personalidade, incluindo aspectos relativos ao desenvolvimento, aos potenciais e fraquezas ${ }^{1,7}$.

Apresentamos, a seguir, uma descrição breve dos tópicos a serem avaliados e registrados com relação à história.

\section{Identificação:}

Nome, sexo, idade, estado civil, grupo étnico, procedência, religião, profissão.

\section{Queixa principal - origem e motivo do enca- minhamento}

Utilizando-se a terminologia do paciente, deve-se fazer uma breve descrição sobre o problema atual para o qual ele está buscando ajuda profissional, ou para o qual foi trazido por outros para o tratamento. É importante observar quem encaminhou, de quem foi a iniciativa de buscar ajuda e com que objetivo.

\section{História da Moléstia Atual:}

Neste tópico, deve-se avaliar como a doença começou, se existiram fatores precipitantes, como evoluiu, qual a gravidade e o impacto da doença sobre a vida da pessoa.

É importante considerar a descrição detalhada dos sintomas, a frequiência, duração e flutuações dos mesmos. Ainda, deve-se observar a seqüência cronológica dos sintomas e eventos relacionados desde as primeiras manifestações até a situação atual.

\section{Antecedentes - História Médica e Psiquiátrica}

Descrever, em ordem cronológica, as doenças, cirurgias e internações hospitalares. Observar o estado atual de saúde, as mudanças recentes de peso, de sono, hábitos intestinais e problemas menstruais.

Colher informações sobre medicamentos em uso $\mathrm{e}$, habitualmente, consumidos verificando dosagem e quem prescreveu. Verificar abuso de medicamentos, de drogas e álcool.

Quanto aos antecedentes psiquiátricos levantar informações sobre os tratamentos prévios, especificando há quanto tempo ocorreram, o tipo e a duração dos mesmos. Verificar a utilização prévia de psicofármacos, especificando tipo e dosagem.

Deve-se incluir, quando for o caso, dados sobre a situação atual de atendimento psiquiátrico, informando sobre o tipo de tratamento, duração e a utilização de psicofármacos.

É importante estar atento ao significado e aos sentimentos do paciente frente a sua história de doença, o impacto sobre a sua vida, os sistemas de apoio com que conta e as expectativas de recuperação.

\section{Antecedentes - História Pessoal:}

\section{a) História pré-natal/nascimento}

Informações sobre a gestação, o parto e as condições do nascimento, incluindo: peso, anoxia, icterícia, distúrbio metabólico. 


\section{b) Infância e desenvolvimento}

Descrever: as condições de saúde; os comportamentos e hábitos com relação ao sono, alimentação; as aquisições de habilidades, incluindo o desenvolvimento motor, da linguagem e o controle esfincteriano; a vida escolar, abrangendo idade de início da aprendizagem, o ajustamento, o temperamento, medos, o relacionamento e interação social.

\section{c) Adolescência}

Descrever: os interesses, as aquisições quanto à vida escolar, a profissionalização ou trabalho, as interações e o relacionamento com familiares e colegas, a sexualidade incluindo a menarca, namoro, a $1^{\mathrm{a}}$ relação sexual, o uso de drogas ou álcool. É importante observar a atitude frente ao crescimento, os sentimentos de isolamento ou depressão e as manifestações de delinqüência.

\section{d) Idade adulta}

Descrever as situações e as atitudes frente ao trabalho, a vida familiar e conjugal, a sexualidade, os relacionamentos e a situação sócio-econômica.

Quanto ao trabalho é importante observar: o tipo de atividade, a evolução, as interrupções, as mudanças, o nível de satisfação e as dificuldades relativas à competência e aos relacionamentos.

A vida familiar e conjugal englobam informações sobre os relacionamentos anteriores, as condições do casamento, as características do cônjuge, separações, a sexualidade, a idade, sexo e as condições físicas e psicológicas dos filhos.

Com relação à sexualidade, colher informações sobre as experiências sexuais, as dificuldades de relacionamento, contracepção, gestações e abortos.

Os relacionamentos englobam a convivência social nas rotinas de vida, no lazer, na situação familiar, de vizinhança e de trabalho.

A situação sócio-econômica deve incluir as condições de moradia, as fontes de provisão de recursos, as dificuldades financeiras e os planos e projetos futuros.

\section{Antecedentes - História Familiar}

Colher informações sobre os pais e irmãos quanto à idade, sexo, nível educacional, atividade profissional, características de personalidade, problemas de saúde, com destaque aos relacionados com à saúde mental. Observar história de adoção, de suicídio e de violação da lei ou dos padrões sociais. Com relação aos irmãos, observar a ordem cronológica de nascimento. Caso os pais ou irmãos sejam falecidos, especificar a causa da morte e a idade na ocasião.

O ambiente familiar: o nível de interação, os padrões de relacionamento dos pais entre si, com os filhos e destes entre si, constitui-se numa informação importante.

\section{Personalidade pré-mórbida}

Compreende o conjunto de atitudes e padrões habituais de comportamento do indivíduo, a descrição deve abarcar o modo de ser habitual do paciente, independente da sua situação de doença. Trata-se de uma tarefa complexa e difícil.

Deve englobar os seguintes aspectos: as preocupações excessivas com ordem, limpeza, pontualidade, o estado de humor habitual, a capacidade de expressar os sentimentos, a maneira como se expressa habitualmente, o nível de desconfiança e competitividade, a capacidade para executar planos e projetos e a maneira como reage quando se sente pressionado.

É importante observar as mudanças de personalidade com a doença.

\section{Exame físico}

Deve ser feito de rotina, visando verificar se os sinais e sintomas estão associados a condições orgânicas ou psiquiátricas.

\section{EXAME DO ESTADO MENTAL}

O exame do estado mental é uma avaliação do funcionamento mental do paciente, no momento do exame, com base nas observações que foram feitas durante a entrevista. Assim, ele pode variar de um momento para outro, em função de mudanças na psicopatologia do paciente. Da mesma forma que o exame físico de um paciente com hipertensão arterial, pode mostrar uma pressão arterial normal, em razão do paciente estar medicado, o exame do estado mental de um esquizofrênico pode deixar de apresentar alucinações, pelo mesmo motivo.

Com o objetivo de facilitar a descrição, o exame do estado mental é organizado por áreas (p.ex., pensamento, senso-percepção, afeto, etc.), embora exista uma grande inter-relação entre estas diferentes áreas. 
As partes que compõem o exame do estado mental e suas principais alterações, são descritas abaixo:

\section{APRESENTAÇÃO GERAL}

Trata-se de uma descrição da impressão geral advinda da aparência física, da atitude e conduta do paciente na interação com o entrevistador.

- Aparência - A descrição deve permitir formar uma imagem sobre o paciente, de forma a reconhecê-lo, englobando:

a) aparência quanto à idade e à saúde;

b) a presença de deformidades e peculiaridades físicas;

c) o modo de vestir-se e os cuidados pessoais, incluindo ordem, asseio e excentricidades;

d) a expressão facial, através da mímica e enquanto sinais sugestivos de doença orgânica, depressão, ansiedade, alegria exagerada ou sem motivo aparente.

\section{- Psicomotricidade}

a) o comportamento e atividade motora, envolvendo a velocidade e intensidade da mobilidade geral na marcha, quando sentado e na gesticulação;

b) a atividade motora, incluindo a agitação (hiperatividade) ou retardo (hipoatividade), a presença de tremores, de acatisia, estereotipias, maneirismos (movimentos involuntários estereotipados), tiques (movimentos involuntários e espasmódicos);

c) a presença de sinais característicos de catatonia (anomalias motoras em distúrbios não orgânicos), como flexibilidade cérea (manutenção de posturas impostas por outros), obediência automática, resistência passiva e ativa, negativismo (resistência imotivada), estupor (lentificação motora, imobilidade) e catalepsia (manutenção de uma posição imóvel).

- Situação da entrevista/interação - Deve-se descrever as condições em que a entrevista ocorreu abrangendo:

a) o local;

b) a presença de outros participantes e

c) intercorrências eventuais

Quanto à interação, deve-se descrever a disponibilidade e interesse frente à entrevista, destacando-se: cooperação, oposição, tendência a conduzir a entrevista, indiferença, negativismo frente ao exame.

\section{LINGUAGEM E PENSAMENTO}

$\mathrm{O}$ examinador tem um acesso indireto ao pensamento do paciente, através do discurso do mesmo durante a entrevista. Assim, a linguagem e o pensamento são avaliadas conjuntamente, nesta parte do exame, segundo os seguintes aspectos:

1- Características da fala - Deve ser anotado se a fala é espontânea, se ocorre apenas em resposta à estimulação ou não ocorre (mutismo). Descreve-se, também, o volume da fala e se ocorre algum defeito na verbalização, tais como: afasia (prejuízo na compreensão ou transmissão de idéias, através da linguagem, que é devido à lesões ou doenças nos centros cerebrais envolvidos com a linguagem ${ }^{8}$ ), disartria (incapacidade na articulação das palavras), gagueira, rouquidão, etc.

2 - Progressão da fala - Deve ser observada a quantidade e a velocidade da verbalização do paciente, durante a entrevista. Algumas alterações possíveis são listadas abaixo:

- Linguagem quantitativamente diminuída - o paciente restringe sua fala ao mínimo necessário, com respostas monossilábicas ou muito sucintas, sem sentenças ou comentários adicionais.

- Fluxo lento - são notadas longas pausas entre as palavras e/ou latência para iniciar uma resposta.

- Prolixidade - o paciente fala muito, discorrendo longamente sobre todos os tópicos, porém ainda dentro dos limites de uma conversação normal.

- Fluxo acelerado - o paciente fala, continuamente, e com velocidade aumentada. $\mathrm{O}$ examinador, geralmente, encontra dificuldade ou não consegue interromper o discurso do paciente.

3 - Forma do pensamento - neste item, deve ser examinada a organização formal do pensamento, sua continuidade e eficácia em atingir um determinado objetivo. Alguns distúrbios observados neste item são:

- Circunstancialidade - o objetivo final de uma determinada fala é longamente adiado, pela incorporação de detalhes irrelevantes e tediosos.

- Tangencialidade - o objetivo da fala não chega a ser atingido ou não é claramente definido. $\mathrm{O}$ paciente afasta-se do tema que está sendo discutido, introduzindo pensamentos aparentemente não relacionados, dificultando uma conclusão. O paciente fala de forma tão vaga, que apesar 
da fala estar quantitativamente adequada, pouca informação é transmitida (pobreza do conteúdo do pensamento).

- Perseveração - o paciente repete a mesma resposta à uma variedade de questões, mostrando uma incapacidade de mudar sua resposta a uma mudança de tópico.

- Fuga de idéias - ocorre sempre na presença de um pensamento acelerado e caracteriza-se pelas associações inapropriadas entre os pensamentos, que passam a serem feitas pelo som ou pelo ritmo das palavras (associações ressonantes).

- Pensamento incoerente - ocorre uma perda na associação lógica entre partes de uma sentença ou entre sentenças (afrouxamento de associações). Numa forma extrema de incoerência, observa-se uma seqüência incompreensível de frases ou palavras (salada de palavras).

- Bloqueio de pensamento - ocorre uma interrupção súbita da fala, no meio de uma sentença. Quando o paciente consegue retomar o discurso, o faz com outro assunto, sem conexão com a ideação anterior.

- Neologismos - o paciente cria uma palavra nova e ininteligível para outras pessoas, geralmente uma condensação de palavras existentes.

- Ecolalia - repetição de palavras ou frases ditas pelo interlocutor, às vezes com a mesma entonação e inflexão de voz.

4 - Conteúdo do pensamento - Neste item, investigam-se os conceitos emitidos pelo paciente durante a entrevista e sua relação com a realidade. Deve-se assinalar:

A -Tema predominante e/ou com características peculiares, tais como:-

- Ansiosos - preocupações exageradas consigo mesmo, com os outros ou com o futuro.

- Depressivos - desamparo, desesperança, ideação suicida, etc.

- Fóbico - medo exagerado ou patológico diante de algum tipo de estímulo ou situação.

- Obsessivos - pensamentos recorrentes, invasivos e sem sentido, que a pessoa reconhece como produtos de sua própria mente e tenta afastá-los da consciência. Podem ser acompanhados de comportamentos repetitivos, reconhecidos como irracionais, que visam neutralizar algum desconforto ou situação temida (Compulsões) ${ }^{8}$.
B - Logicidade do pensamento, ou o quanto o pensamento pode ser sustentado por dados da realidade do paciente. Alguns tipos de pensamento ilógico são descritos abaixo:

- Idéias supervalorizadas - o conteúdo do pensamento centraliza-se em torno de uma idéia particular, que assume uma tonalidade afetiva acentuada, é irracional, porém sustentada com menos intensidade que uma idéia delirante.

- Delírios - crenças que refletem uma avaliação falsa da realidade, não são compartilhadas por outros membros do grupo sócio-cultural do paciente e das quais não pode ser dissuadido, através de argumentação contrária, lógica e irrefutável ${ }^{1}$.

Os delírios podem ser primários, quando não estão associados a outros processos psicológicos, p.ex., inserção de pensamento (crê que pensamentos são colocados em sua cabeça), irradiação de pensamento (acredita que os próprios pensamentos são audíveis ou captados pelos outros) e secundários, quando vinculados a outros processos psicológicos( derivados de uma alucinação, associados à depressão ou mania) ${ }^{7}$.

Os delírios podem ser descritos em função de seu grau de organização, em: sistematizados (relacionados a um único tema, mantendo uma lógica interna, ainda que baseada em premissas falsas, o que pode conferir maior credibilidade) e não sistematizados (quando envolvem vários temas, são mais desorganizados e pouco convincentes). Os delírios podem ser descritos, também, pelo seu tema predominante, p. ex., como delírio de referência (atribuição de um significado pessoal a observações ou comentários neutros), persecutório (idéia de que está sendo atacado, incomodado, prejudicado, perseguido ou sendo objeto de conspiração), de grandiosidade (o conteúdo envolve poder, conhecimento ou importância exagerados), somáticos (o conteúdo envolve uma mudança ou distúrbio no funcionamento corporal), de culpa (acredita ter cometido uma falta ou pecado imperdoável), de ciúmes (acredita na infidelidade do parceiro), de controle (acredita que seus pensamentos, sentimentos e ações são controlados por alguma força externa) ${ }^{8}$.

5 - Capacidade de abstração - reflete a capacidade de formular conceitos e generalizações. A incapacidade de abstração é referida como pensamento concreto. Este item pode ser avaliado, através 
da observação de algumas manifestações espontâneas, durante a entrevista (p.ex., diante da pergunta "como vai" o paciente responde "vou de ônibus"), ou através da solicitação para que o paciente interprete provérbios habituais para sua cultura.

\section{SENSO - PERCEPÇÃO}

O examinador deverá avaliar se as sensações e percepções do paciente resultam da estimulação esperada dos correspondentes órgãos do sentido. Para isso, pode valer-se de relatos espontâneos de percepções alteradas; da observação de comportamentos sugestivos de percepções, na ausência de estímulos externos (conversar consigo mesmo, rir sem motivo, olhar repentinamente em determinada direção, na ausência de estímulo aparente); ou, ainda, pode formular perguntas diretas sobre tais alterações (p.ex., "Você já teve experiências estranhas, que a maioria das pessoas não costumam ter?" "Você já ouviu barulhos ou vozes, que outras pessoas, estando próximas, não conseguiram ouvir?"). As principais alterações da senso-percepção são comentadas abaixo:

- Despersonalização: refere-se à sensação de estranheza, como se seu corpo, ou partes dele não lhe pertencessem, ou fossem irreais.

- Desrealização: o ambiente ao redor parece estranho e irreal, como se "as pessoas ao seu redor estivessem desempenhando papéis".

- Ilusão: interpretação perceptual alterada, resultante de um estímulo externo real.

- Alucinações: percepção sensorial na ausência de estimulação externa do órgão sensorial envolvido. As alucinações podem ser: auditivas (sons ou vozes; as vozes podem dirigir-se ao paciente ou discutirem entre si sobre ele), visuais (luzes ou vultos até cenas em movimento, nítidas e complexas), táteis (toque, calor, vibração, dor, etc.), olfatórias e gustativas. As alucinações que ocorrem no estado de sonolência, que precede o sono (hipnagógicas) e no estado semiconsciente, que precede o despertar (hipnopômpicas) são associadas ao sono normal e não são, necessariamente, patológicas.

\section{AFETIVIDADE E HUMOR}

A avaliação do afeto inclui a expressividade, o controle e a adequação das manifestações de sentimentos, envolvendo a intensidade, a duração, as flutuações do humor e seus componentes somáticos. Considera-se humor a tonalidade de sentimento mantido pelo paciente durante a avaliação. Para a avaliação desta função considera-se:

a) o conteúdo verbalizado;

b) o que se observa ou se deduz do tom de voz, da expressão facial, da postura corporal;

c) a maneira como o paciente relata experimentar os próprios sentimentos, o que pode requerer um questionamento específico sobre "como os sentimentos são experimentados", e

d) o relato de oscilações e variações de humor no curso do dia.

- Tonalidade emocional: avalia-se a tonalidade emocional predominante durante a entrevista, observando-se a presença e a intensidade de manifestações de: ansiedade, pânico, tristeza, depressão, apatia, hostilidade, raiva, euforia, elação, exaltação, desconfiança, ambivalência, perplexidade, indiferença, embotamento afetivo (virtualmente, sem expressão afetiva, p. ex. voz monótona, face imóvel ${ }^{8}$ ).

- Modulação: Refere-se ao controle sobre os afetos, deve-se observar a presença de hipomodulação, associada à rigidez afetiva, caracterizada pela manutenção de uma certa fixidez no afeto externalizado, e de hipermodulação, associada à labilidade afetiva, caracterizada por marcadas oscilações no humor manifesto.

- Associação pensamento/afeto: A avaliação da relação do conteúdo do pensamento ao afeto manifesto constitui-se em ponto importante, devendo-se considerar: o nível de associação / dissociação e a adequação / inadequação das manifestações, para tal deve-se levar em conta a temática e o contexto na qual ela está inserida.

- Equivalentes orgânicos: Os equivalentes ou concomitantes orgânicos do afeto devem ser avaliados com base nas alterações do apetite, peso, sono e libido.

É importante observar na avaliação desta a função, a presença de manifestações ou risco de auto e heteroagressividade, tais como idéias ou planos de suicídio, ou ainda idéias ou projetos de homicídio ou agressão voltada para o meio.

Deve-se considerar, ainda, na avaliação desta função as manifestações relativas a auto-estima, e a volição, enquanto a energia que a pessoa está investindo e a disposição com a qual está se envolvendo na realização de seus projetos pessoais. 
Os sentimentos despertados no avaliador durante a entrevista, podem também ser um recurso útil na avaliação do afeto, para tal é necessário que o entrevistador seja mais experiente e capaz de perceber os elementos transferenciais.

\section{ATENÇÃO E CONCENTRAÇÃO}

$\mathrm{Na}$ avaliação é considerada a capacidade de focalizar e manter a atenção em uma atividade, envolvendo a atenção/distração, frente aos estímulos externos ou internos. Esta função quando prejudicada interfere, diretamente, no curso da entrevista, requerendo que o entrevistador repita as perguntas feitas. A avaliação pode envolver, além da observação da própria situação de entrevista, a proposição de tarefas/ testes simples como:

a) dizer os dias da semana e os meses do ano em uma dada ordem proposta pelo entrevistador, e

b) realizar cálculos simples. A complexidade das tarefas deve levar em conta o nível sócio-cultural do paciente avaliado. É importante observar o quanto a dificuldade está associada à atenção ou relacionada a um distúrbio de ansiedade, do humor ou da consciência

- Manutenção prejudicada: dificuldade de manter a atenção focalizada sobre os estímulos mais relevantes do meio, desviando a atenção para os estímulos irrelevantes e exigindo intervenções do entrevistador para manter a atenção focalizada nos estímulos principais.

- Focalização prejudicada: dificuldade de focalizar a atenção sobre os estímulos mais relevantes do meio, não atendendo às intervenções do entrevistador.

- Desatenção Seletiva: desatenção frente a temas que geram ansiedade.

\section{MEMÓRIA}

A memória começa ser avaliada durante a obtenção da história clínica do paciente, com a verificação de como ele se recorda de situações da vida pregressa, tais como, onde estudou, seu primeiro emprego, perguntas sobre pessoas significativas de sua vida passada, tratamentos anteriores, etc. A memória pode ser avaliada, também, através de testes específicos, alguns deles bastante simples, e que podem ser introduzidos numa entrevista psiquiátrica habitual. A investigação da memória é, particularmente, importante quando se suspeita de quadros de etiologia orgânica. Habitualmente, divide-se a avaliação da memória em três tipos:

- Memória Remota: avalia a capacidade de recordar-se de eventos do passado, podendo ser avaliada durante o relato feito pelo paciente, de sua própria história.

- Memória Recente: avalia a capacidade de recordar-se de eventos que ocorreram nos últimos dias, que precederam a avaliação. Para esta avaliação o examinador pode perguntar sobre eventos verificáveis dos últimos dias, tais como: o que o paciente comeu numa das refeições anteriores, o que viu na TV na noite anterior, etc.

- Memória Imediata: avalia a capacidade de recordar-se do que ocorreu nos minutos precedentes. Pode ser testada, pedindo-se ao paciente que memorize os nomes de três objetos não relacionados e depois de 5 minutos, durante os quais se retomou a entrevista normal, solicitando-se que o paciente repita esses três nomes.

Ao observar-se uma deficiência de memória é importante, para alguns diagnósticos diferenciais, verificar-se como o paciente lida com ela, ou seja: tem uma reação catastrófica, diante da deficiência; nega ou tenta não valorizar o déficit de memória; preenche lacunas de memória com recordações falsas (confabulação).

\section{ORIENTAÇÃO}

A avaliação envolve aspectos auto e alopsíquicos.

- Autopsíquica: Os aspectos autopsíquicos se caracterizam pelo reconhecimento de si envolvendo:

a) saber o próprio nome;

b) reconhecer as pessoas do seu meio imediato, através de seu nome ou de seu papel social e

c) saber quem é o entrevistador.

- Alopsíquica: Com relação aos aspectos alopsiquícos são avaliados:

a) a orientação no tempo, englobando saber informar - o ano, o mês, o dia da semana, o período do 
dia, ou ainda a estação do ano, ou marcos temporais como Natal/ Carnaval/ Páscoa;

b) a orientação no espaço envolve saber informar onde se encontra no momento, nomeando o lugar, a cidade e o estado.

\section{CONSCIÊNCIA}

Neste item, deve ser registrado o nível de consciência do paciente, dentro do contínuo que vai desde o estado de consciência plena (percebe o que ocorre a sua volta e responde à essa percepção) até o coma (não responde à estimulação em diferentes graus). Esta avaliação decorre do contacto com o paciente durante a entrevista. Algumas alterações de consciência são descritas abaixo:

- Sonolência: lentificação geral dos processos ideacionais, com predisposição para dormir, na ausência de estimulação.

- Obnubilação da consciência: diminuição do nível de vigília, acompanhado de dificuldade em focalizar a atenção e manter um pensamento ou comportamento objetivo.

- Estupor: permanece em mutismo e sem movimentos, com preservação relativa da consciência.

- Delirium: quadro agudo caracterizado por diminuição do nível de vigília, acompanhado de alterações cognitivas (desorientação, déficits de memória) ou perceptuais (ilusões e alucinações).

- Estado crepuscular: estreitamento da consciência, podendo manter comportamentos motores relativamente organizados, na ausência de um estado de consciência plena. Ocorre, predominantemente, em estados epilépticos.

\section{CAPACIDADE INTELECTUAL}

A avaliação desta função, de forma empírica na situação de entrevista, envolve uma estimativa do nível de desempenho intelectual esperado, em função da escolaridade e do nível sócio-cultural, enquanto capacidade de compreensão e integração de experiências.

Trata-se de uma função complexa, pois seu comprometimento pode refletir o prejuízo de outras fun- ções como pensamento, atenção - concentração, ou ainda a não aquisição de habilidades, em função de baixa escolaridade ou de experiência em um meio sócio-cultural pobre.

Na situação de entrevista deve ser observado: o vocabulário, sua propriedade e nível de complexidade, e a capacidade de articular conceitos, de abstrair e generalizar.

- Prejuízo intelectual: Para a avaliação deste item, a observação da situação de entrevista, pode ser complementada com a proposição de atividades como:

a) perguntas que avaliam as informações sobre assuntos ou temas gerais (por exemplo, quem é o Presidente da República);

b) a resolução de problemas aritméticos (por exemplo, quanto receber de troco em uma situação de compra e venda);

c) a leitura de textos escritos comentando a compreensão dos mesmos. É importante observar o nível sócio-cultural do paciente na seleção das atividades e na complexidade das mesmas.

- Deterioração: Deve-se estar atento à presença de uma deterioração global, com prejuízo no funcionamento intelectual, sem obnubilação da consciência no caso de demência (disfunção cerebral orgânica) ou pseudodemência (depressão).

A avaliação psicodiagnóstica, através dos testes específicos de inteligência, deve ser solicitada quando foi observado na entrevista a presença de déficits específicos.

\section{JUÍZO CRÍTICO DA REALIDADE}

Esta avaliação deve ser feita durante a obtenção da história do paciente, sendo os testes formais de pouca utilidade. Objetiva verificar se as ações do paciente são determinadas por uma avaliação coerente da realidade, do ponto de vista do funcionamento mental e da capacidade adaptativa, incluindo o nível realista dos projetos e da avaliação das próprias realizações. Considera-se que o juízo crítico da realidade está alterado, por exemplo, quando as decisões do paciente são determinadas por delírios ou alucinações. 
ZUARDI AW \& LOUREIRO SR. Psychiatric semiology. Medicina, Ribeirão Preto, 29: 44-53, jan./mar. 1996.

ABSTRACT: The main objective of this article is to introduce undergraduate students, especially of medicine, in the practice of psychiatric semiology. The authors discuss the psychiatric interview as the essential way for assessment of the psychiatric patient. The article provides an outline of a psychiatric history and of the component parts of the mental status examination, including: appearance; speech and thought; perceptual disturbances; affect and mood; attention and concentration; memory; orientation; consciousness; intelligence; and reality judgment.

UNITERMS: Medical History Taking. Psychiatry. Physician - Patient Relations. Mental Status

\section{REFERÊNCIAS BIBLIOGRÁFICAS}

1 - KAPLAN HI \& SADOCK BJ Compêndio de psiquiatria dinâmica. Artes Médicas, Porto Alegre, p. 153-181, 1984: Diagnóstico e psiquiatria: o exame do paciente psiquiátrico.

2 - BLEGER J. Temas de psicologia: Entrevista e grupos 7. reimp. Martins Fontes, São Paulo, p. 9-41, 1995: A entrevista psicológica: seu emprego no diagnóstico e na investigação.

3 - MacKINNON RA \& MICHELS R. A entrevista psiquiátrica na prática clínica. Artes Médicas, Porto Alegre, p. 15-62, 1981: Princípios gerais da entrevista.

4 - MUCCHIELLI R. A entrevista não diretiva 2. ed. Martins Fontes, São Paulo, p. 30-37, 1994: A situação de entrevista e suas variáveis específicas.
5 - DEL PORTO JA. Visão geral sobre os instrumentos para obtenção de informações (entrevistas estruturadas e semi-estruturadas). Rev. ABP/APAL, 8 (Supl):18-24, 1986.

6 - DRATCU L. O exame do paciente psiquiátrico. In: ALMEIDA OP; DRATCU L \& LARANJEIRA R ed. Manual de psiquiatria. Guanabara Koogan, Rio de Janeiro, p. 5-21, 1996

7 - SCHEIBER SC The psychiatric interview, psychiatric history, and mental status examination. In: HALES RE; YODOESKY SC \& TALBOTT JA The american psychiatric press: Textbook of psychiatry. 2th. ed, American Psychiatric Press, Washington, p.187-219, 1994.

8 - AMERICAN PSYCHIATRIC ASSOCIATION. Diagnostic and statistical manual of mental disorders. 4th. ed. American Psychiatric Association, Washington, 1994.

Recebido para publicação em 04/03/96

Aprovado para publicação em 14/03/96 